Artigo original

Hegemonia - Revista Eletrônica de Relações Internacionais do Centro Universitário Unieuro

ISSN: 1809-1261

UNIEURO, Brasília, número 5, 2010

Recebido em: 6/1/2010

Revisado em: 5/2/2010

Aprovado em: 10/3/2010

\title{
TERRORISMO E RELIGIÃO: UM ESTUDO SOBRE A ATUAÇÃO DO REGIME TALIBAN À LUZ DA IDEOLOGIA ISLÂMICA
}

\author{
DE SOUZA, Geila Carla ${ }^{1}$ \\ SANTOS, Alexandre Hamilton Oliveira ${ }^{2}$
}

Resumo: O terrorismo e a religião islâmica é um tema antigo que está continuamente presente no noticiário cotidiano, e já faz parte da história contemporânea, mais na atualidade se ver pouco material escrito explicando sobre as suas verdadeiras causas, e menos ainda sobre o movimento ideológico islâmico. O presente artigo tem como escopo fazer uma análise através de uma revisão bibliográfica sobre o terrorismo e religião, enfocando especificamente a atuação do regime Taliban à luz da ideologia islâmica.

Palavras-Chave: Terrorismo, religião, ideologia islâmica, regime Taliban

\begin{abstract}
Terrorism and Islam is an old theme that is continually present in the daily news, and is now part of contemporary history, but nowadays there are not many written material explaining about the real causes, and even less about the Islamic ideological movement. Thus, this article aims to provide an analysis, by a literature review on religion and terrorism, focusing specifically on the actions of the Taliban regime in the light of Islamic ideology
\end{abstract}

Key-words: Terrorism, religion, Islam, Taliban

\section{INTRODUÇÃO}

Praticamente em todas as religiões pode-se encontrar o fundamentalismo religioso, durante todas as épocas da história da humanidade. Os Fundamentalistas são os mais conservadores e obstinados seguidores de uma religião. A guerra contra o terrorismo gerou mudanças no Taliban, mas não em seu fundamentalismo religioso islâmico.

Aqui, parte-se do entendimento que, a religião tem ocupado um papel dominante na análise da problemática do terrorismo internacional, ou seja, a religião tem ocupado um papel dominante na

\footnotetext{
1 Mestranda do Programa de Mestrado em Ciência Política do Centro Universitário Euro-Americano UNIEURO

2 Doutor em Integração da América Latina (PROLAM/USP) e Professor do Programa de Mestrado em Ciência Política do Centro Universitário Euro-Americano - UNIEURO (CV Lattes: http://lattes.cnpq.br/6117549370157309)
} 
Artigo original

Hegemonia - Revista Eletrônica de Relações Internacionais do Centro Universitário Unieuro

ISSN: 1809-1261

UNIEURO, Brasília, número 5, 2010

análise da problemática entre o mundo ocidental e o islã.

A importância do tema abordado localiza-se no sentido de que o regime Taliban adota um postura contraditória aos preceitos originais do islamismo, o qual condena o terrorismo e opressão, muito embora, faça apologia à Jihad, a Guerra Santa.

No presente trabalho, em questão, percebe-se que a citada prática islâmica é levada às últimas conseqüências, aviltando o próprio fiel do islã. Desta forma, o trabalho se mostra relevante porque traduz a outra face do islã que foge à regra dos princípios básicos do alcorão levando ao leitor a conhecer o lado cruel e opressor daqueles que praticam a religião e a transformou em um movimento terrorista. São apontadas circunstâncias de um período antes e depois do regime Taliban, marcado pelo fanatismo ideológico e religioso.

Desde o fim da Guerra Fria, o terrorismo religioso tem ressurgido com uma terrível vingança. O fanatismo religioso tem sido um capítulo comentado constantemente na sociedade atual. Grupos extremistas e terroristas têm deixado suas marcas sangrentas e abomináveis por diversos países do mundo. O terror tem sido espalhado como forma de amedrontar e intimidar povos e governos e, muitas vezes o terrorismo tem sido praticado com fins políticos e econômicos, não somente como fim religioso.

\section{TERRORISMO: UMA ABORDAGEM CONCEITUAL}

Terrorismo é um termo plural, dotado de muitas significados, que apresenta muitos problemas para ser definido devido a sua ambigüidade. Em virtude disso, apresenta sérios obstáculos para estabelecer fronteiras conceituais ou um escopo em torno de sua concepção. Para muitos especialistas, tal fato explica a razão pela qual a comunidade internacional não consegue delimitá-lo criando uma noção que contemple toda sua plenitude e complexidade, e, o que é mais importante, que atenda aos interesses de todos ou da maioria (SANTOS, 2008).

Originariamente, é um vocábulo que deriva da palavra "terror" que surgiu na língua francesa (“terreur"), em 1335, e vem do latim terror, cuja noção, na origem, referia-se a "um medo ou uma 
Artigo original

Hegemonia - Revista Eletrônica de Relações Internacionais do Centro Universitário Unieuro ISSN: 1809-1261

UNIEURO, Brasília, número 5, 2010

ansiedade extrema, correspondendo, com mais freqüência, a uma ameaça vagamente percebida, pouco familiar e largamente imprevisível” (GUILLAUME, 1989, p. 296, apud PELLET, 2003).

Na Revolução Francesa, ao final do século XVIII, o termo "terror" adquire uma nova noção tornando-se uma forma de governo. Em seguida à Lei de 22 Prairial (nono mês do calendário republicano) do ano II, um tribunal revolucionário encarrega-se de criar o "terror", privando os acusados de defensores, impondo a supressão da audição de testemunhas e decretando somente a pena de morte, sem possibilidade de apelação ou recurso. Neste período, mais ou menos 1.380 opositores à Revolução foram guilhotinados em apenas 49 dias. Esta violência política, conduzida no bojo da revolução, tinha como objetivo contribuir para "desenvolver o sentimento de solidariedade nacional", restaurando ou impondo a autoridade do novo Estado francês sob a autoridade do então líder Robespierre.

Em virtude das mudanças de condução das políticas por parte dos revolucionários, as medidas de terror foram cessadas e Robespierre perdeu seu poder. Em 9 Themidor (décimo primeiro mês do calendário republicano) do ano II, Robespierre é condenado e guilhotinado pelos membros da Convenção por “Terrorismo”, considerando que estes últimos não poderiam responsabilizá-lo pelo terror que eles próprios haviam defendido (AULARD, 1901, p.. 358, apud PELLET, 2003).

O Terror deste modo passou a ser um meio de legítima defesa da ordem social usado pela Revolução, foi substituído pelo terrorismo, que passou a visar unicamente o terror exercido abusivamente pelo Estado. É neste momento que terror tornou-se terrorismo, mais especificamente terrorismo revolucionário, termo em que se misturam direito e política, fato este que causa problema de definição do termo, já mencionado, até hoje tanto na esfera interna quanto na esfera internacional.

Com relação ainda à passagem do terror para o terrorismo, somente no final do século XIX que reaparece a palavra "terrorismo" e com novo sentido, e isso se deu através do terrorismo dos anarquistas, os quais buscavam aterrorizar o Estado incitando a sociedade contra os órgãos estatais, por meio da propaganda. Data também desta mesma época o surgimento do terrorismo dos niilistas na Rússia, que chegaram a assassinar o Czar Alexandre II, em $1^{\circ}$ de março de 1981 . O que se vê é um terrorismo até então utilizado como um meio de ação cujo objetivo era mudar o status quo 
Artigo original

Hegemonia - Revista Eletrônica de Relações Internacionais do Centro Universitário Unieuro ISSN: 1809-1261

UNIEURO, Brasília, número 5, 2010

político numa tentativa de derrubar o poder estabelecido em um determinado país. Em suma, tanto o terrorismo revolucionário da Revolução Francesa quanto o tipo de terrorismo utilizado pelos anarquistas e niilistas, focavam exclusivamente a ordem interna do Estado em que atuavam, o que muito se diferencia do que ocorre no terrorismo internacional.

O terrorismo internacional passou a receber atenção pela primeira vez quando da realização de debates acerca do assunto nas Conferências Internacionais para a Unificação do Direito Penal, a partir de 1927. Após algumas tentativas fracassadas de negociação, foi somente na $6^{\text {a }}$ Conferência, ocorrida em Copenhague em 1935, que oito artigos, precedidos de um preâmbulo, são adotados. Este texto preconizava a abertura no código penal ou em uma lei especial uma seção ou um capítulo intitulado "Dos atentados que criam um perigo comum ou um estado de terror", sendo que uma descrição dos fatos que tipificaria esta categoria deveria seguir a legislação (SOTTILE, 1938, p. 113-115 apud PELLET, 2003).

Pellet (2003) cita que o nascimento de fato do que seria desde então reconhecido como terrorismo internacional na sociedade internacional se deu através do assassinato, por um terrorista croata, em 9 de outubro de 1934, em Marselha, do Rei Alexandre I da Iugoslávia e do Ministro Francês de Assuntos Estrangeiros, Louis Barthou.

Em virtude dos assassinatos supracitados, os debates se acirraram no Conselho das Sociedades das Nações, e o Presidente do Conselho, Pierre Laval, instou a todos a refletir sobre a necessidade de criação de uma regulamentação internacional que assegurasse uma repressão eficaz dos crimes políticos. Assim, a iniciativa francesa proporcionou o surgimento de trabalhos do Comitê para a Repressão Internacional do Terrorismo, que elaborou dois projetos de Convenção adotados em 16 de dezembro de 1937, em Genebra.

A primeira Convenção foi assinada por 24 Estados. A segunda, que tratava da criação de uma Corte Penal Internacional competente para julgar indivíduos acusados de ações terroristas, foi assinada somente por 13 Estados. Apesar da iniciativa não ter logrado êxito, a tentativa de regulamentação do terrorismo internacional permitiu avanços acerca da matéria no direito internacional e, em especial, despertou interesse pelo assunto.

Com o aumento do número de casos de seqüestros de aviões nos anos 60 , a comunidade 
Artigo original

Hegemonia - Revista Eletrônica de Relações Internacionais do Centro Universitário Unieuro ISSN: 1809-1261

UNIEURO, Brasília, número 5, 2010

internacional retoma sua luta contra o terrorismo internacional e, para tanto, surgiu uma multiplicidade de Convenções internacionais (SANTOS, 2008b).

\section{ALGUMAS ESPECIFICIDADES DO REGIME TALIBAN}

Fundado por Maomé no séc. VII da era cristã na Arábia como uma religião monoteísta, baseada na escritura sagrada, o Alcorão, e que determina aos fiéis o rigor em suas práticas convertendo-se numa força unificadora de diversos povos, trazendo coesão e impulsionando a época, uma expansão territorial até o ocidente que perdurou por 14 séculos.

O Islã, segundo Magnoli, é uma religião predominante nos países árabes e o alicerce histórico das sociedades árabes é a cultura muçulmana, contudo, o mundo árabe não se define pela língua, mas pela religião. Assim, a religião tem sido a mola-mestra que impulsiona os ataques terroristas no regime Taliban. Contudo, não se deve analisar a religião islâmica como sendo uma religião violenta, antes deve fazer uma análise do contexto de uma cultura em que a religião é o centro da sociedade.

Os movimentos fundamentalistas islâmicos desenvolveram-se durante o século XX em reação a variedade de acontecimentos. Um exemplo de fundamentalismo e o islamismo que já nasceu fundamentalista não admitindo um mundo que esteja fora das linhas de seu livro sagrado, o Alcorão. Neste sentido, o fundamentalismo é definido como um movimento de ideário, de apelo aos fiéis para que sigam os mandamentos do profeta Maomé irrestritamente, mantendo a unidade religiosa e a pureza.

De acordo com Huntington, (1997, p.273), o problema subjacente para o Ocidente não é o fundamentalismo islâmico. É o Islã, uma civilização diferente, cujas pessoas estão convencidas da superioridade de sua cultura e obcecadas com a inferioridade de seu poderio. O problema para o Islã não e a CIA ou o Departamento de Defesa dos Estados Unidos. É o Ocidente, uma civilização diferente cujas pessoas estão convencidas da universalidade de sua cultura e acreditam que seu poderio superior, mesmo que em declínio, lhes impõem a obrigação de estender sua cultura por todo o mundo. 
Artigo original

Hegemonia - Revista Eletrônica de Relações Internacionais do Centro Universitário Unieuro ISSN: 1809-1261

UNIEURO, Brasília, número 5, 2010

Os fundamentos corânicos do Islã não prevêem a separação entre religião e política. Segundo ainda Magnoli, "as esferas da religião e da política manifesta-se no plano jurídico. Logo, para falar, de aspectos culturais, políticos, jurídicos, sociais do Taliban, recorresse ao Alcorão, livro sagrado do Islã, conseqüentemente, do regime Taliban.

Observa-se que o Alcorão é a justiça, a cultura, a política de um povo que vive à luz da ideologia islâmica. Ou seja, não há outros meios se não for pela religião. Esta prevalece, salva e mata, é pacífica, mas também vingativa. Não somente o islamismo, mas muitas outras religiões têm empreendido guerras, terror em nome de um Deus que é paz e amor. A religião tem levado multidões à guerra, com propósito de alcançar a paz, ou seja, uma religião que deveria trazer paz, comete a violência em nome de Deus.

Para Procópio (2001), há uma domesticação do terror e banalização da vida em uma apropriação em nome de Deus, os homens praticam atrocidades. E, contudo, o nome de Deus tem sido usado em vão.

A domesticação do terror da violência com a banalização do valor da vida, em flagrante desrespeito ao próximo e aos direitos humanos, mais a apropriação do nome de Deus no combate ao terror entre as partes conflitantes [...] complicam enormemente a arena da ética antiterrorista. A invocação do nome de Deus deveria preocupar as diferentes confissões religiosas. (PROCÓPIO, p. 70, 2001).

No "fundamentalismo islâmico, a humilhação política e a pobreza econômica funcionam como seus motores. O Ocidente é o inimigo, representado pelos Estados Unidos e, regionalmente, por Israel" (MAGNOLI, p 306, 2004).

O regime Taliban é caracterizado pela opressão e a brutalidade exercida contra o povo afegão, tratase de uma ameaça não só ao ocidente, mas também ao próprio mundo islâmico. De acordo com Christopher Catherwood (2008, p. 189) em todo o mundo o terrorismo ressurgiu com uma terrível vingança, em especial, desde o fim da guerra fria. Segundo o autor:

[...] lo que vimos resurgir después del final del la guerra fría en 1991 y lo que golpeó a los Estados Unidos con una violencia tan terrible el 11/9 no es demasiado diferente de lo que impulso la conquista de Jerusalén en los 
Artigo original

Hegemonia - Revista Eletrônica de Relações Internacionais do Centro Universitário Unieuro ISSN: 1809-1261

UNIEURO, Brasília, número 5, 2010

años 638 y 1099: la guerra en nombre de una creencia religiosa (CATHERWOOD, 2008, p. 190).

A religião tem se tornado um aspecto de poder e violência para alguns países árabes. No regime Taliban, o Estado fica em segundo lugar, a religião exerce um poderio ilimitado, pois os muçulmanos têm o Alcorão como seu guia de cultura, política e justiça.

\section{CONSIDERAÇÕES FINAIS}

O presente artigo teve como objetivo fazer uma pequena correlação entre terrorismo e religião, enfocando, especificamente, a atuação do regime Taliban, à luz da ideologia islâmica. Assim sendo, a partir dos aspectos essenciais ora apresentados sobre o tema pode-se preliminarmente concluir que, o terrorismo é um fenômeno antigo e complexo, com definições variadas, ligados a aspectos políticos, culturais, econômicos e religiosos que envolvem poder e dominação, seja cultural, territorial ou através da economia globalizada.

Pode-se inferir também que os elementos básicos que alimentam o conflito entre o Islã e o Ocidente são: o convencimento da superioridade cultural e inferioridade bélica do Islã, em contraponto à universalidade e ao poderio bélico superior ocidental. Para Cretella Neto (2008), é preciso saber discernir terrorismo de terrorismo islâmico, apenas este último constitui ameaça para países como EUA e aliados, que têm uma visão distorcida sobre o Islã.

O “fundamentalismo" Islâmico, comumente concebido como o Islamismo político, é apenas um dos componentes numa revitalização muito mais extensa das idéias, práticas e retórica islâmicas e no reengajamento no Islamismo pelas populações muçulmana”. (HUNTINGTON, P.135, 1997).

O mundo pós-guerra fria e conseqüentemente um mundo mais globalizado, colocou as diferentes culturas num contato mais direto, fazendo com que aumentasse a percepção e diferenças entre si. Logo, é mais provável que coalizões existem entre Estados ou entidades da mesma civilização, nesse caso, o conflito entre islã e ocidente não terá um fim, pois são culturas diferentes. $\mathrm{O}$ terrorismo religioso não será banido se as pessoas continuarem usando a religião como fator principal para desencadear uma guerra. Por esta razão que Procópio advoga que o sentido espiritual da Jihad, Guerra Santa, "precisa ser respeitado e conhecido no Ocidente”(2001). 
Artigo original

Hegemonia - Revista Eletrônica de Relações Internacionais do Centro Universitário Unieuro ISSN: 1809-1261

UNIEURO, Brasília, número 5, 2010

\section{REFERÊNCIAS BIBLIOGRÁFICAS}

CATHERWOOD, Christopher Guerras en Nombre de Dios; traducción de Victoria Vera. - $1^{\text {a }}$ ed.. Buenos Aires: El Ateneo, 2008. - 219 p.

CRETELLA NETO, José. Terrorismo Internacional. Campinas, SP, Millennium Editora, 2008.

GUILLAUME (G), Terrorisme et Droit International, R.C.A.D.I., vol. 215, 1989-III, p. 296.

HUNTINGTON, Samuel. O Choque de civilizações e a recomposição da nova ordem mundial. Rio de janeiro: Objetiva, 1997.

MAZETTO, Francisco de Assis Penteado. O terrorismo no Brasil. Centro de Pesquisas Estratégicas "Paulino Soares de Souza". Juiz de Fora, MG: Universidade Federal de Juiz de Fora, 2003.

PELLET, Alain. Terrorismo e guerra. O que fazer das Nações Unidas? IN:Terrorismo e direito. Os impactos do terrorismo na comunidade internacional e no Brasil / Coordenador , Leonardo Nemer Caldeira Brant. - Rio de Janeiro: Forense, 2003.

PROCÓPIO, Argemiro. Terrorismo e relações internacionais. Brasília. Ver. Bras. Polít. Int. 44(2): 62-81. 2001.

SANTOS, Alexandre Hamilton O. Regime Internacional de Segurança de Aviação Civil: Um Estudo de Análise da Política de Transporte Aéreo da América Latina Pós-Atentados Terroristas de 11 de setembro de 2001 nos Estados Unidos da América. Tese de Doutorado apresentada no Programa de Pós-Graduação de Integração da América Latina da Universidade de São Paulo, 2008. 